\title{
Annual Wellness Visits for Persons With Physical Disabilities Before and After ACA Implementation
}

Tanima Basu, MA, MS

Neil Kamdar, $M A^{1}$

Patrick Brady, MHA ${ }^{1}$

Cristin M. Cole, $M P H$

Jaque King, MPP ${ }^{2}$

Robyn Rontal, JD, MHSA ${ }^{2}$

Diane M. Harper, MD, MPH, MS

'University of Michigan, Institute for Healthcare Policy \& Innovation, Ann Arbor, Michigan

${ }^{2}$ University of Michigan, Center for Health and Research Transformation, Ann Arbor, Michigan

${ }^{3}$ University of Michigan, Departments of Family Medicine, Obstetrics/ Gynecology, Bioengineering, Women's \& Gender Studies, IHPI, Ann Arbor, Michigan

Conflicts of interest: authors report none.

\section{CORRESPONDING AUTHOR}

Diane M. Harper 1018 Fuller Street Ann Arbor, MI 48104 harperdi@med.umich.edu

\begin{abstract}
PURPOSE Persons with disabilities often experience uncoordinated health care, with repeated out-of-pocket copays. One purpose of the Patient Protection and Affordable Care Act (ACA) was to create zero copays for preventive health care including an annual wellness visit (AWV). The purpose of this study was to document the use of AWVs by persons with physical disabilities during the ACA rollout.
\end{abstract}

METHODS An administrative claims database, including both Medicare Advantage (MA) and commercial (COM) payers from 2008 to 2016, was used to identify unique wellness visits for adults with physical disabilities. We used interrupted time series analysis to compare AWV use by insurance type, sex, disability type, and race over time.

RESULTS The proportion of zero copays provided a timeline of ACA implementation categorized as pre-ACA, ACA-implementation, and post-ACA periods. By 2016, AWV use maximized at 47.6\% (95\% Cl, 44.7\%-50.8\%) among COMinsured White women with congenital disabilities. By 2016, the lowest AWV use reached one-half the maximum, at $21.6 \%(95 \% \mathrm{Cl}, 18.4 \%-25.2 \%)$ among COMinsured Hispanic men with acquired disabilities. MA-insured Black and Hispanic men with acquired disabilities reached similarly low levels of AWV use.

CONCLUSIONS The ACA mandated zero copays, thereby allowing persons with physical disabilities the option for preventive health care without cost. Insurance type and sex significantly influenced AWV use, followed by disability type and race. Gaps in AWV use were exposed by insurance type, sex, disability, and race for persons with disabilities. Gaps in AWV use were also exposed between the general population and persons with disabilities.

Ann Fam Med 2021;19:484-491. https://doi.org/10.1370/afm.2712.

Annals "Online First" article.

\section{INTRODUCTION}

T mproving health for persons with disabilities is a relatively recent commitment in the United States. Healthy People 2010 (HP2010) was the first set of health targets to include goals for persons with disabilities, ${ }_{1}{ }^{1}$ occurring in response to the 2005 Surgeon General's call to action. ${ }^{2}$ The HP2010 final report indicated that 11 of the 81 targets for persons with disabilities had been met. ${ }^{3}$

In 2010, the Patient Protection and Affordable Care Act of 2010 (ACA) was passed to increase the use of preventive services among all people aged $\geq 18$ years by providing designated preventive services, including annual wellness visits (AWVs), at no cost to the enrollee., ${ }^{4,5}$ Annual wellness visits include assessment of medical, family, and social history including alcohol, tobacco, and drug use; diet and physical activity; vital signs such as blood pressure, weight, height, and visual acuity; cognitive or functional impairments; risk factors for depression or mood disorders; and personalized health advice to decrease risk factors for chronic diseases. Unlike specific single prevention goals, such as blood pressure check, which are not linked to increased use of other broad preventive services, ${ }^{6}$ some reports 
have shown that the use of AWVs increases the likelihood of having more expansive preventive screenings such as immunizations, cancer screenings, depression screening, and cardiovascular screening. ${ }^{7-10}$

Adults with physical disabilities have more chronic illnesses than the general population, ${ }^{11}$ have 3 times more unmet health care needs than nondisabled persons, ${ }^{12}$ and have increased needs for primary and secondary prevention compared with the general population. ${ }^{13}$ Despite these increased needs, there is a gap in existing knowledge regarding the use of AWVs in this adult population. Increasing AWV use might be one way to increase the overall health of persons with disabilities.

The present study focuses on persons with physical ambulatory disabilities who have either Medicare Advantage (MA) or commercial (COM) insurance and their use of AWVs from 2008 to 2016. Using zero copay as an indicator of ACA implementation timing and the removal of a cost barrier, our aim was to measure changes in AWV use throughout the ACA timeframe for adults with congenital or acquired physical disabilities.

\section{METHODS}

\section{Data Source}

We obtained administrative claims from the Optum Clinformatics Data Mart (CDM) database (Optum Inc) for the study period January 1, 2008 to December 31, 2016. The CDM, representing deidentified MA and COM enrollees with medical and pharmacy coverage throughout their insurance enrollment, is described elsewhere. ${ }^{14}$

\section{Patient Population}

We selected adults aged $\geq 18$ years who had a diagnosis of cerebral palsy, spina bifida, multiple sclerosis, spinal cord injury, hemiplegia, paraplegia, or quadriplegia during the calendar year of enrollment using International Classification of Diseases, 9th and 10th Revisions, 15,16 diagnostic codes (Supplemental Table 1, https://www. AnnFamMed.org/lookup/suppl/doi:10.1370/afm.2712/-/ DC1). To be included in the study, we required patients to be continuously enrolled during a given calendar year (Supplemental Figure 1, https://www. AnnFamMed.org/lookup/suppl/doi:10.1370/afm.2712/-/ DC1). Cerebral palsy and spina bifida were considered congenital conditions, and the remainder were considered acquired conditions.

This was a quasiexperimental, repeated, crosssectional study given that each patient-calendar year could reflect a slightly different patient population for which outcomes were measured. For example, for adults with congenital conditions, a patient's first year in the study was defined as the date of diagnosis at any point during that year or before the study period, with the same insurance group and with continuous enrollment. For adults with acquired conditions, a patient's first year in the study was defined as the year after the date of initial diagnosis. We then examined all subsequent years that that patient had a full calendar year of enrollment with the same insurance company for inclusion in the study population. Patients could move in and out of each calendar year. For hierarchical classification, we prioritized congenital disabilities with appropriate clinical consultation and feasibility. Given that this study could reflect underlying changes in patient population over time, key stratifications based on payer, disability, sex, and race were examined.

\section{Outcome Variables}

The primary outcome was AWV use during the full calendar year that the patient was enrolled in the plan. Patient copayment for the AWV during the same study period was used to define the 3 time frames of the study: before ACA (pre), during ACA (implementation), and after ACA (post). AWVs were identified from medical claims using Current Procedural Terminology codes for preventive visits for those aged $<65$ years as new (99385-99387) or established (99395-99397) and AWVs for those aged $\geq 65$ years as first (G0438) and subsequent (G0439) during the calendar year.

\section{Statistical Analysis}

Annual wellness visit use was calculated by the number of persons with $\geq 1$ coded AWV in a 12-month time frame divided by the number of persons with specified disabilities enrolled in that year. For the uncommon situation in which a person had $>1$ AWV coded during a 12 -month time frame, we censored subsequent codes. We calculated the proportion of zero copays using the number of persons who had zero copays for the specific service year divided by all users for that calendar year.

To examine the effect of the ACA on AWV use across various strata, we implemented an interrupted time series analysis (ITSA) design with 3 phases. We considered 2008-2010 to be the pre-ACA period (the time frame before its legality was established). The post-ACA period was defined as 2014-2016 given that this was the stable period with zero copayments after the 2011-2013 years of ACA implementation. Because the ACA underwent phased implementation, most notably for the commercially insured population with grandfathered plans that were not subject to ACA requirements, the gradual changes in cost and use during the implementation period took several years. 
The ITSA models used an ordinary least-squares approach. As reported ${ }_{1}^{17}$ underlying assumptions for ITSA require that preintervention trends for each group be linear, which can be confirmed via visual inspection or statistical analysis of linear trend with a sufficient number of time points. Interrupted time series analysis models also assume that the parameter estimates are not controlled for other covariates that would traditionally be considered for risk adjustment. A prevailing assumption is that the characteristics of the population remain unchanged throughout the study period, and any changes in the underlying population characteristics cannot be directly attributable to the outcome. Race, sex, and insurance strata predicated on the aforementioned assumptions were used to conduct comparisons on use and copayments using multiple group ITSA. ${ }^{17}$

To assess the effect of the ACA, we performed a series of multiple-group ITSAs with a lag using ordinary least-squares estimation while accounting for autocorrelation, as described previously. ${ }^{17-19}$ The selection of the appropriate lag is critical, based on autocorrelation testing, to examine the adequacy of the time-series model based on whether tests and CIs on the regression coefficients are satisfactorily estimated. We used Cumby-Huizinga general tests for autocorrelation to establish the appropriate lag for the ITSA models to ensure accurate estimation of intervention and trend effects.

The demographic characteristics of the population were compared with $t$ tests for age as a continuous variable and with $\chi^{2}$ testing for all categorical variables. All analyses were conducted using SAS version 9.4 (SAS Institute Inc) and Stata version 15.0 (StataCorp LLC). All statistical testing was 2-tailed with an $\alpha \leq .05$.

\section{RESULTS}

From 2008 to 2016, a total of 317,188 unique individuals were identified, of which 317,134 had complete data for insurance and demographic variables. The COM group was significantly younger and more female, predominantly White, and had different proportions of congenital and acquired disabilities compared to the MA group (Supplemental Table 2, https://www.AnnFamMed.org/ lookup/suppl/doi:10.1370/afm.2712/-/DC1).

Patients with spina bifida (3.6\%), cerebral palsy $(6.1 \%)$, and multiple sclerosis (27.1\%) were significantly younger than those with the other disabilities (spinal cord injury [14.6\%], paraplegia [5.1\%], quadriplegia [2.5\%], and hemiplegia [41.0\%]) (Table 1). Among all patients, multiple sclerosis, spina bifida, spinal cord injury, and hemiplegia occurred significantly more often in females than in males. The most common disability was hemiplegia among Asian patients (3.2\%), quadriplegia among Black (15.8\%) and Hispanic patients $(13.6 \%)$, and multiple sclerosis among White patients $(80.6 \%)$. Those with acquired disabilities had $\mathrm{MA}$ insurance significantly more often than those with congenital disabilities.

\section{By Insurance}

Before the ACA, AWV use among MA members in 2008 was $11.4 \%$ (95\% CI, 10.7\%-12.1\%), and that for COM members was $31.3 \%$ (95\% CI, 30.6\%-32.1\%). After full ACA implementation in 2016, AWV use among MA members (31.0\% [95\% CI, 30.7\%-31.7\%]) increased the most (trend $=4.39 ; 95 \% \mathrm{CI}, 2.61 \%-6.17 \%$ ) but still remained significantly less than that for COM members (38.0\% [95\% CI, 37.0\%-38.5\%]) (Figure 1, Supplemental Table 3, https://www.AnnFamMed.org/ lookup/suppl/doi:10.1370/afm.2712/-/DC1). In addition, the rate of increase of AWVs over the 3 time frames was dominated by insurance status (Supplemental Table 3).

\section{By Disability}

Before the ACA, AWV use among those with congenital disabilities (23.1\% [95\% CI, 21.9\%-24.3\%]) was significantly less than that among those with acquired disabilities (25.5\% [95\% CI, 24.9\%-26.2\%]) (Supplemental Table 3). By 2016, AWV use had increased for both disability types, with post-ACA use trends of 2.95 (95\% CI, 1.95-3.95) and 2.48 (95\% CI, 0.95-4.02) for congenital and acquired disabled persons, respectively; however, AWV use was no different between congenital and acquired disabilities.

Disability evaluated by insurance membership showed that post ACA, MA-insured adults with acquired or congenital disabilities both had significantly fewer AWVs (Figure 2A, B) compared with respective COM members (Figure 2C, D). Whereas there was no difference in AWVs by disability for COM members (Figure 2C and Figure 2D), MA members with acquired disabilities had significantly fewer AWVs than those with congenital disabilities (Figure 2A, B).

\section{By Sex}

Before the ACA, initial AWV use among men (11.4\% [95\% CI, 10.8\%-12.1\%]) was approximately one-third that among women (33.0\% [95\% CI, 32.2\%-33.8\%]) (Supplemental Table 3). By 2016, whereas men significantly increased AWV use (28.5\%), it was still significantly less than women's AWV use (36.8\%). Rates of AWV use over the 3 time frames differed significantly by sex as well. Women had decreasing rates of AWV use during the pre-ACA period, increasing during ACA implementation, with yet greater increases in the post-ACA period (Supplemental Table 3). Men had a 
Table 1. Population Description by Physical Disability Type

\begin{tabular}{|c|c|c|c|c|c|c|c|c|c|}
\hline & \multicolumn{2}{|c|}{$\begin{array}{l}\text { Congenital } \\
\text { Disabilities }\end{array}$} & \multicolumn{5}{|c|}{ Acquired Disabilities } & \multirow[b]{2}{*}{ Total } & \multirow[b]{2}{*}{$\begin{array}{c}P \\
\text { Value }\end{array}$} \\
\hline & $\begin{array}{l}\text { Spina } \\
\text { Bifida }\end{array}$ & $\begin{array}{c}\text { Cerebral } \\
\text { Palsy }\end{array}$ & $\begin{array}{l}\text { Multiple } \\
\text { Sclerosis }\end{array}$ & $\begin{array}{l}\text { Spinal Cord } \\
\text { Injury }\end{array}$ & Paraplegia & Quadriplegia & Hemiplegia & & \\
\hline No. & 11,339 & 19,319 & 85,925 & 46,340 & 16,253 & 7,862 & 130,096 & 317,134 & \\
\hline Age, y, mean (SD) & $\begin{array}{c}44.4 \\
(16.5)\end{array}$ & $\begin{array}{c}48.0 \\
(18.8)\end{array}$ & $\begin{array}{l}51.5 \\
(14.4)\end{array}$ & $\begin{array}{c}62.1 \\
(18.8)\end{array}$ & $\begin{array}{c}64.4 \\
(15.7)\end{array}$ & $\begin{array}{c}65.8 \\
(16.4)\end{array}$ & $\begin{array}{l}69.0 \\
(14.1)\end{array}$ & $\begin{array}{l}60.8 \\
(17.7)\end{array}$ & \\
\hline $\begin{array}{l}\text { Age group, y, } \\
\text { No. (\%) }\end{array}$ & & & & & & & & & $<.001$ \\
\hline $18-65$ & $\begin{array}{l}9,851 \\
(86.9)\end{array}$ & $\begin{array}{l}15,314 \\
(79.3)\end{array}$ & $\begin{array}{c}70,831 \\
(82.4)\end{array}$ & $\begin{array}{c}22,976 \\
(49.6)\end{array}$ & $\begin{array}{l}7,624 \\
(46.9)\end{array}$ & $\begin{array}{l}3,308 \\
(42.1)\end{array}$ & $\begin{array}{l}42,990 \\
(33.0)\end{array}$ & $\begin{array}{c}172,927 \\
(54.5)\end{array}$ & \\
\hline$>65$ & $\begin{array}{l}1,488 \\
(13.1)\end{array}$ & $\begin{array}{l}4,005 \\
(20.7)\end{array}$ & $\begin{array}{l}15,094 \\
(17.6)\end{array}$ & $\begin{array}{c}23,364 \\
(50.4)\end{array}$ & $\begin{array}{l}8,629 \\
(53.1)\end{array}$ & $\begin{array}{l}4,554 \\
(57.9)\end{array}$ & $\begin{array}{l}87,106 \\
(67.0)\end{array}$ & $\begin{array}{c}144,240 \\
(45.5)\end{array}$ & \\
\hline Sex, No. (\%) & & & & & & & & & $<.001$ \\
\hline Female & $\begin{array}{l}7,664 \\
(67.6)\end{array}$ & $\begin{array}{l}9,481 \\
(49.1)\end{array}$ & $\begin{array}{l}63,753 \\
(74.2)\end{array}$ & $\begin{array}{c}25,063 \\
(54.1)\end{array}$ & $\begin{array}{l}7,244 \\
(44.6)\end{array}$ & $\begin{array}{l}3,902 \\
(49.6)\end{array}$ & $\begin{array}{c}69,059 \\
(53.1)\end{array}$ & $\begin{array}{c}186,166 \\
(58.7)\end{array}$ & \\
\hline Male & $\begin{array}{l}3,675 \\
(32.4)\end{array}$ & $\begin{array}{l}9,838 \\
(50.9)\end{array}$ & $\begin{array}{c}22,172 \\
(25.8)\end{array}$ & $\begin{array}{r}21,277 \\
(45.9)\end{array}$ & $\begin{array}{l}9,009 \\
(55.4)\end{array}$ & $\begin{array}{l}3,960 \\
(50.4)\end{array}$ & $\begin{array}{l}61,037 \\
(46.9)\end{array}$ & $\begin{array}{c}130,968 \\
(41.3)\end{array}$ & \\
\hline Race, No. (\%) & & & & & & & & & $<.001$ \\
\hline Asian & $\begin{array}{l}238 \\
(2.4)\end{array}$ & $\begin{array}{l}408 \\
(2.4)\end{array}$ & $\begin{array}{c}1,259 \\
(1.7)\end{array}$ & $\begin{array}{l}1,166 \\
(2.9)\end{array}$ & $\begin{array}{l}367 \\
(2.6)\end{array}$ & $\begin{array}{c}184 \\
(2.7)\end{array}$ & $\begin{array}{c}3,627 \\
(3.2)\end{array}$ & $\begin{array}{l}7,250 \\
(2.6)\end{array}$ & \\
\hline Black & $\begin{array}{l}1,120 \\
(11.3)\end{array}$ & $\begin{array}{l}2,090 \\
(12.4)\end{array}$ & $\begin{array}{l}7,546 \\
(10.1)\end{array}$ & $\begin{array}{l}4,115 \\
(10.2)\end{array}$ & $\begin{array}{l}2,046 \\
(14.5)\end{array}$ & $\begin{array}{l}1,072 \\
(15.8)\end{array}$ & $\begin{array}{l}17,657 \\
(15.7)\end{array}$ & $\begin{array}{c}35,654 \\
(13.0)\end{array}$ & \\
\hline Hispanic & $\begin{array}{c}989 \\
(10.0)\end{array}$ & $\begin{array}{l}1,526 \\
(9.1)\end{array}$ & $\begin{array}{c}5,354 \\
(7.6)\end{array}$ & $\begin{array}{c}3,672 \\
(9.1)\end{array}$ & $\begin{array}{l}1,604 \\
(11.4)\end{array}$ & $\begin{array}{c}928 \\
(13.6)\end{array}$ & $\begin{array}{l}11,573 \\
(10.3)\end{array}$ & $\begin{array}{c}25,646 \\
(9.3)\end{array}$ & \\
\hline White & $\begin{array}{l}7,536 \\
(76.3)\end{array}$ & $\begin{array}{l}12,764 \\
(76.0)\end{array}$ & $\begin{array}{l}60,030 \\
(80.6)\end{array}$ & $\begin{array}{l}31,302 \\
(77.8)\end{array}$ & $\begin{array}{l}10,109 \\
(71.6)\end{array}$ & $\begin{array}{l}4,622 \\
(67.9)\end{array}$ & $\begin{array}{l}79,781 \\
(70.8)\end{array}$ & $\begin{array}{c}206,144 \\
(75.0)\end{array}$ & \\
\hline Insurance, No. (\%) & & & & & & & & & $<.001$ \\
\hline $\begin{array}{l}\text { Medicare } \\
\text { Advantage }\end{array}$ & $\begin{array}{l}2,777 \\
(24.5)\end{array}$ & $\begin{array}{l}9,431 \\
(48.8)\end{array}$ & $\begin{array}{c}28,135 \\
(32.7)\end{array}$ & $\begin{array}{c}25,249 \\
(54.5)\end{array}$ & $\begin{array}{l}11,096 \\
(68.3)\end{array}$ & $\begin{array}{l}5,098 \\
(64.8)\end{array}$ & $\begin{array}{c}93,883 \\
(72.2)\end{array}$ & $\begin{array}{c}175,669 \\
(55.4)\end{array}$ & \\
\hline Commercial & $\begin{array}{l}8,562 \\
(75.5)\end{array}$ & $\begin{array}{l}9,888 \\
(51.2)\end{array}$ & $\begin{array}{c}57,790 \\
(67.3)\end{array}$ & $\begin{array}{c}21,091 \\
(45.5)\end{array}$ & $\begin{array}{l}5,157 \\
(31.7)\end{array}$ & $\begin{array}{l}2,764 \\
(35.2)\end{array}$ & $\begin{array}{l}36,213 \\
(27.8)\end{array}$ & $\begin{array}{c}141,465 \\
(44.6)\end{array}$ & \\
\hline
\end{tabular}

minimal positive rate of AWV use in the pre-ACA period but during ACA implementation significantly surpassed women's rate of AWV use and matching women's post-ACA rate.

\section{By Race}

Black and Hispanic patients had the lowest AWV use in 2008 (Black: $19.6 \%$ [95\% CI, 18.1\%-21.2\%], Hispanic: $21.7 \%$ [95\%. CI, 19.8\%23.8\%]) compared to White patients (26.1\% [95\% CI, 25.4\%-26.7\%]), and despite varying increases in use over time, had the lowest AWV use in 2016 (Black: 30.1\% [95\% CI, 29.2\%31.1\%], Hispanic: $30.1 \%$ [95\% CI, 29.2\%-31.1\%]) compared with White patients (34.3\% [95\% CI, 33.9\%34.7\%]) (Supplemental Table 3). The

\section{Figure 1. Establishment of ACA intervals by proportion of annual} wellness visits with zero copay.

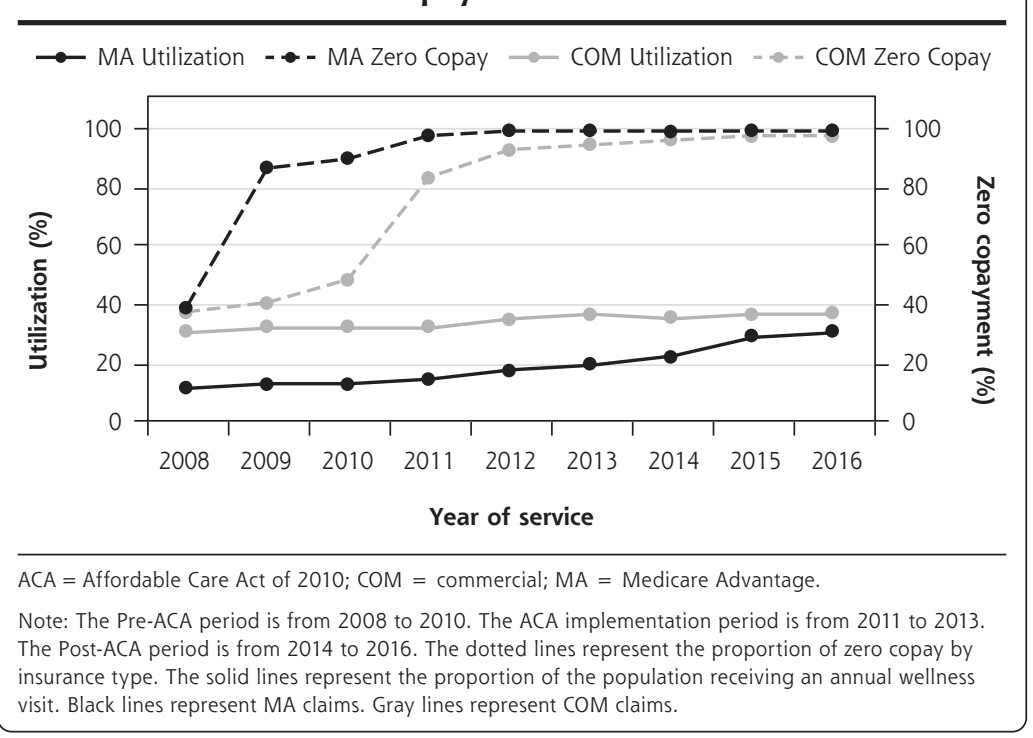


rate of $\mathrm{AWV}$ use over the 3 time frames by race was different than those for insurance, sex, and disability. In the pre-ACA period, White patients had a greater decrease in AWV use compared to Black patients (Supplemental Table 3), but in the post-ACA period, there was no difference in AWV use by race. All copays went to zero, owing to implementation of the ACA. Further stratification by insurance, sex, disability, and race are presented in Supplemental Table 4 (https:// www.AnnFamMed.org/lookup/suppl/doi:10.1370/ afm.2712/-/DC1), Supplemental Table 5 (https://www. AnnFamMed.org/lookup/suppl/doi:10.1370/afm.2712/-/ DC1), Supplemental Table 6 (https://www.AnnFam Med.org/lookup/suppl/doi:10.1370/afm.2712/-/DC1),

\section{Figure 2. Proportion of zero copay and annual wellness visits by insurance, disability, and sex.}

A. Annual wellness visits among MA insured, with congenital disability, by sex.

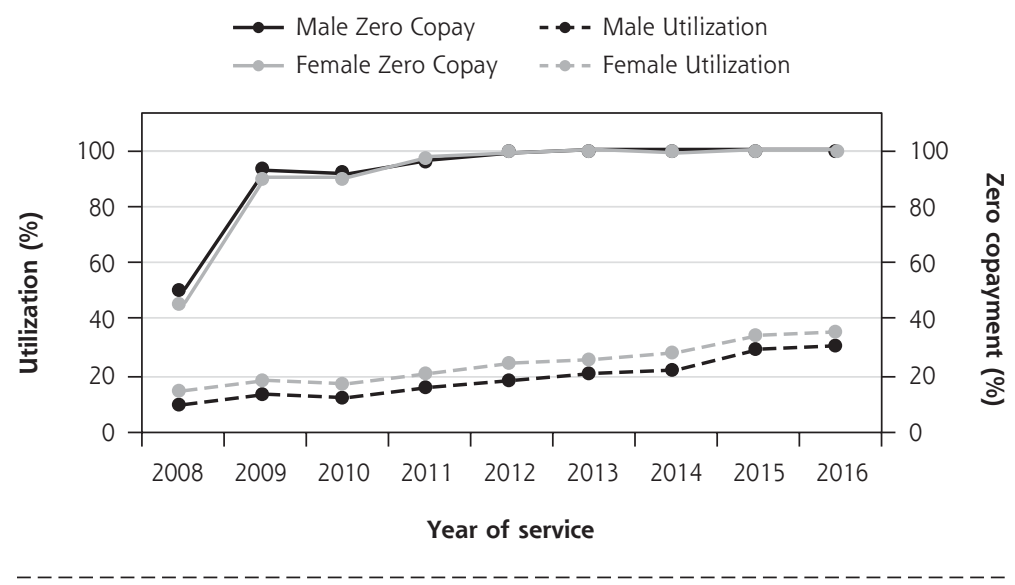

B. Annual wellness visits among MA insured, with acquired disability, by sex.

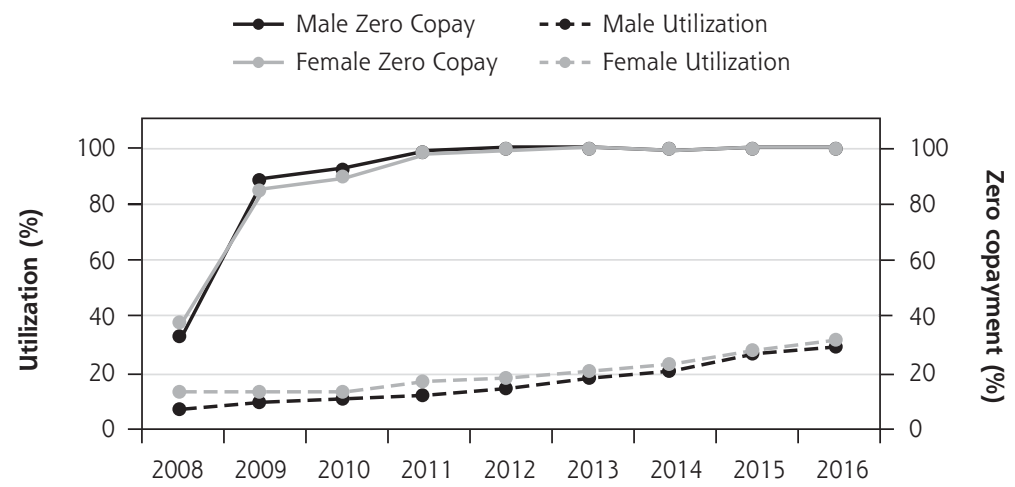

Year of service

ACA = Affordable Care Act of 2010; COM = commercial; MA = Medicare Advantage

Note: The Pre-ACA period is from 2008 to 2010. The ACA implementation period is from 2011 to 2013. The Post-ACA period is from 2014 to 2016. The solid lines represent the proportion of individuals with zero copay. The dotted lines represent utilization rate. Gray lines represent female. Black lines represent male. continues

Supplemental Figure 2 (https://www.AnnFamMed.org/ mental Figure 3 (https://www.AnnFamMed.org/lookup/ suppl/doi:10.1370/afm.2712/-/DC1/).

\section{DISCUSSION}

The results of the present study show how AWV use White women with congenital disabilities. By 2016 , the lowest AWV use reached one-half the maximum, at $21.6 \%(95 \% \mathrm{CI}, 18.4 \%-25.2 \%)$ among COM-insured

Hispanic men with acquired disabilities. MA-insured Black and Hispanic men with acquired disabilities reached similarly low levels of AWV use. In addition, our data showed that implementation of the ACA required a 3-year time frame to reach complete zero copay for 2 different health insurance types. Our rigorous definition of ACA time frames allowed for 3 evaluation periods of AWV use, whereas most other research has dichotomized the ACA without regard to an intermediary period of change, ${ }^{6,20-22}$ which was necessary for this population.

We found that during the preACA period (2008-2010), women with physical disabilities, who had gained the greatest AWV use of all persons with disabilities, were decreasing their rate of attendance at AWVs at the same time both the Surgeon General and HP2010 were encouraging AWVs specifically for persons with disabilities. ${ }^{2,3}$ Whereas this negative trend was also seen among those with congenital disabilities and among White patients, all groups increased rate and use of AWVs during the implementation phase of the ACA (2011-2013). Both rates and use continued to increase for all groups except those with COM insurance post ACA, when zero copays had been firmly established.

The rates of increase in AWV use exposed 2 gaps: (1) the maximal AWV use achieved by White women with congenital disabilities and COM 


\section{Figure 2. Proportion of zero copay and annual wellness visits by insurance, disability, and sex. (continued)}

C. Annual wellness visits among СОМ insured, with congenital disability, by sex.

$$
\begin{aligned}
& \rightarrow \text { Male Zero Copay } \quad \text { - Male Utilization } \\
& \ldots \text { Female Zero Copay } \quad \ldots \text { - Female Utilization }
\end{aligned}
$$

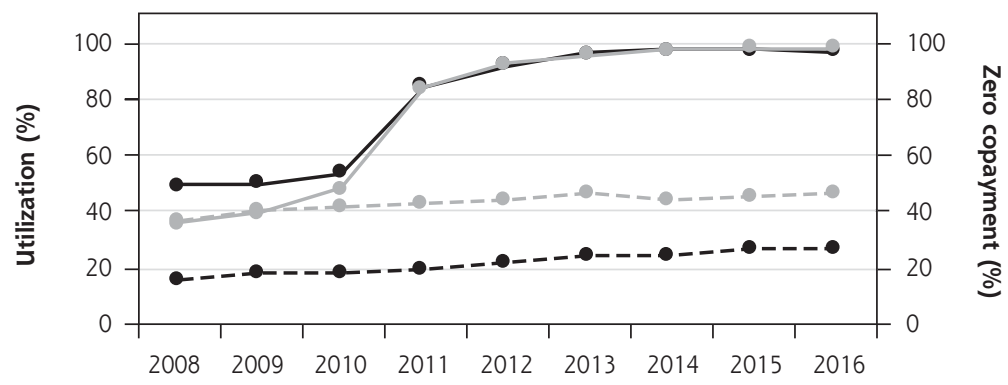

Year of service

D. Annual wellness visits among СОМ insured, with acquired disability, by sex.

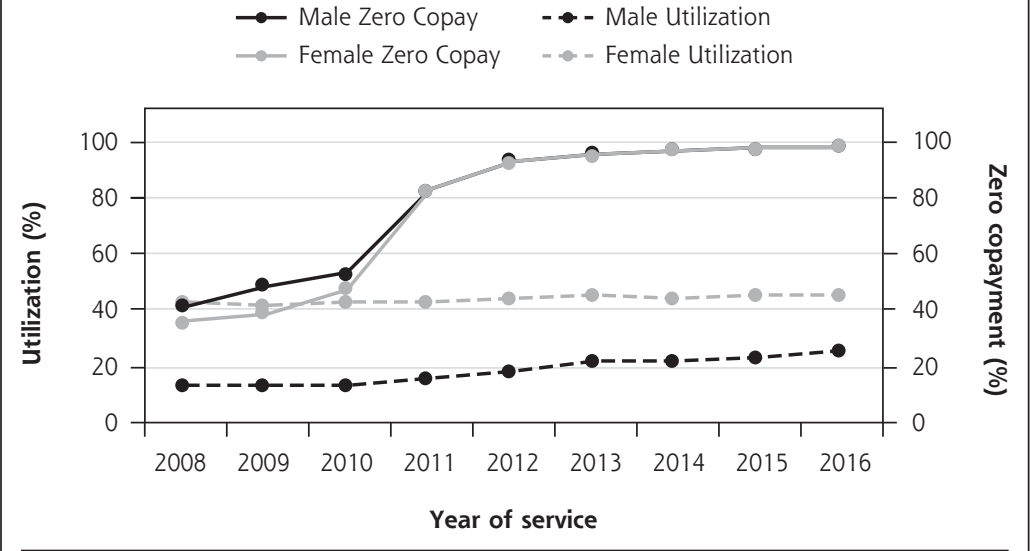

ACA = Affordable Care Act of 2010; $C O M=$ commercial; $M A=$ Medicare Advantage.

Note: The Pre-ACA period is from 2008 to 2010. The ACA implementation period is from 2011 to 2013. The Post-ACA period is from 2014 to 2016. The solid lines represent the proportion of individuals with zero copay. The dotted lines represent utilization rate. Gray lines represent female. Black lines represent male.

insurance was more than twice that of the lowest AWV use for COM-insured Black/Hispanic males with acquired disabilities, which was the same as that for all MA members; (2) the greatest AWV use for persons with disabilities was nearly $15 \%$ less than the $62 \%$ AWV use threshold seen in the general population. ${ }^{20}$

We do not understand the reasons why MA members with disabilities were successful in increasing their AWV use but then stopped short of closing the gap with COM members. Social determinants of health are likely to be one set of effectors of ability to uptake AWVs, ${ }^{7,22-25}$ where the development of 5 place-based domains of economic stability, education, health and health care, neighborhood/built environment, and social/community context most affect population health. Likewise, we do not understand why AWV use among COM members differed so much by sex and race. We did show that COM members were younger than MA members, and other work in the general population shows that younger people use preventive care $50 \%$ more than those aged $>65$ years. ${ }^{26}$ Other work has also shown that men in the general population with COM insurance are much less likely to get preventive health care than women when cost is not a barrier to care. ${ }^{27,28}$ Likewise, masculine norms among men aged $<65$ years prevent participation in preventive care, ${ }^{29}$ whereas among men aged $>65$ years, those most likely to have MA insurance seek similar preventive care as women. ${ }^{30}$ Our results show that among MA members, both men and women had similar AWV use throughout the ACA phases, perhaps indicating that cost barriers, while important, are only a part of the solution to increasing AWV use.

Race continued to be a part of the differences in AWV use over the study time span. As we described, only White women with congenital disabilities were able to decrease the gap between MA insurance and COM insurance to reach an AWV use that closed in on the use that COM members with disabilities experienced. Black and Hispanic patients with disability showed significantly lower AWV use across the ACA time frames. This has also been reported in the general population; compared to White patients, both Black and Hispanic patients had fewer preventive health care visits post ACA. ${ }^{31}$ It is unlikely that race itself drives the AWV use pattern; rather it could be some combination of the local social determinants of health experienced by each population of persons with disabilities.

Disabilities themselves should drive preventive care use, given that preventive care use is recommended to help prevent chronic diseases experienced by those with spina bifida, ${ }^{32,33}$ cerebral palsy, ${ }^{34-38}$ or spinal cord injuries. ${ }^{39-41}$ There are recommendations regarding control of hypertension, diabetes, and cholesterol to prevent second strokes ${ }^{42}$ but little regarding actual primary prevention of those risk factors for persons 
with paralyses. Again, whereas there are national organizational recommendations for preventive care, ${ }^{43-45}$ women with multiple sclerosis have been shown to have fewer annual primary care physician visits $(61 \%)^{46}$ compared to the general population $(84.3 \%) .{ }^{47}$

\section{Study Strengths and Limitations}

The present study has several strengths in leveraging large administrative claims from both COM and MA insurances. Our large, single-private-payer database maintains substantial market penetration throughout the United States, covering a large sample of physically disabled individuals from which we gained insight regarding the use of AWVs during the ACA time frame. A second strength of large administrative claims data sets is that sufficient enrollment in a plan allows for assessment of multiple calendar years and longitudinal follow-up or long cross-sections of time to assess service use. Finally, the use of a single, large, private payer controls for some between-payer variability in cost and coverage for services that might exist in other multipayer databases.

A limitation of administrative claims databases is that we could only document prevalence of AWV use by population strata as they were coded. Therefore, we could not obtain or infer reasons for AWV use, including whether zero copay was a priority, or disability severity itself. Because the single-private-payer database is not geographically representative, our results are not nationally generalizable within the United States. In addition, the subset of persons with disabilities studied are not generalizable to all persons with disabilities because persons with disabilities are also covered by Medicare fee for service or Medicaid.

\section{CONCLUSIONS}

Annual wellness visits provide an opportunity to assess broad health parameters for upcoming decision points in a person's health care. The decreasing rate of AWV use reversed at the inception of the ACA, with continued increased use for persons with physical disabilities. Gaps remain in AWV use between those with MA and COM insurance. In addition, gaps remain between AWV use among persons with disabilities and the general population.

To read or post commentaries in response to this article, go to https://doi.org/10.1370/afm.2712.

Key words: ACA; annual wellness visits; persons with disabilities

Submitted July 15, 2020; submitted, revised, January 21, 2021; accepted February 3, 2021.

Funding support: 90RTHF0001-02-00 (Meade) Administration for Community Living (NIDILRR) - Rehabilitation Research and Training
Center (RRTC) on Promoting Healthy Aging for People with Long-Term Physical Disabilities; P30CA046592 NCI Comprehensive Cancer Center UL1TR001070 National Center for Advancing Translational Science.

Acknowledgments: We would like to acknowledge Dawn Russell for making group meeting arrangements.

- Supplemental materials: Available at https://www.AnnFamMed. org/lookup/suppl/doi:10.1370/afm.2712/-/DC1.

\section{References}

1. Centers for Disease Control and Prevention. CDC grand rounds: public health practices to include persons with disabilities. MMWR Morb Mortal Wkly Rep. 2013;62(34):697-701.

2. US Department of Health and Human Services. The Surgeon General's Call to Action to Improve the Health and Wellness of Persons With Disabilities. Office of the Surgeon General; 2005.

3. National Center for Health Statistics. Healthy People 2010 Final Review; 2012.

4. Chait N, Glied S. Promoting prevention under the Affordable Care Act. Annu Rev Public Health. 2018;39:507-524.

5. Senate and House of Representatives of the United States of America. HR 3590. Patient Protection and Affordable Care Act. Published Mar 23, 2010. Accessed Aug 26, 2018. https://www.gpo.gov/fdsys/ pkg/BILLS-111hr3590enr/pdf/BILLS-111hr3590enr.pdf

6. Han X, Robin Yabroff K, Guy GP Jr, Zheng Z, Jemal A. Has recommended preventive service use increased after elimination of costsharing as part of the Affordable Care Act in the United States? Prev Med. 2015;78:85-91.

7. Carter EA, Lind K, Miller CN. Annual wellness visits among Medicare Advantage enrollees. Trends, differences by race and ethnicity, and association with preventive service use. AARP Public Policy Institute. Published May 14, 2019. Accessed Apr 12, 2020. https://www.aarp.org/ppi/info-2019/annual-wellness-visits-amongmedicare-advantage-enrollees.html

8. Camacho F, Yao NA, Anderson R. The effectiveness of Medicare wellness visits in accessing preventive screening. J Prim Care Community Health. 2017;8(4):247-255.

9. Ganguli I, Souza J, McWilliams JM, Mehrotra A. Trends in use of the US Medicare annual wellness visit, 2011-2014. JAMA. 2017;317(21): 2233-2235.

10. Ganguli I, Souza J, McWilliams JM, Mehrotra A. Association of Medicare's annual wellness visit with cancer screening, referrals, utilization, and spending. Health Aff (Millwood). 2019;38(11): 1927-1935.

11. Centers for Diseases Control and Prevention. Disability and health promotion; disability datasets. Updated Sep 16, 2020. https://www. cdc.gov/ncbddd/disabilityandhealth/datasets.html

12. McColl MA, Jarzynowska A, Shortt SED. Unmet health care needs of people with disabilities: population level evidence. Disability \& Society. 2010;25(2):205-218.

13. McColl MA, Gupta S, Smith K, McColl A. Promoting long-term health among people with spinal cord injury: what's new? Int J Environ Res Public Health. 2017;14(12):1520.

14. UnitedHealth Group. Optum. Accessed Jun 14, 2021. https://www. unitedhealthgroup.com/who-we-are/businesses/optum.html

15. International Classification of Diseases, Ninth Revision. World Health Organization; 1980.

16. International Classification of Diseases, Tenth Revision. World Health Organization; 1992.

17. Kontopantelis E, Doran T, Springate DA, Buchan I, Reeves D. Regression based quasi-experimental approach when randomisation is not an option: interrupted time series analysis. BMJ. 2015;350: h2750. 
18. Linden A. Conducting interrupted time-series analysis for singleand multiple-group comparisons. Stata J. 2015;15(2):480-500.

19. Linden $A$. Challenges to validity in single-group interrupted time series analysis. J Eval Clin Pract. 2017;23(2):413-418.

20. Hong YR, Jo A, Mainous AG III. Up-to-date on preventive care services under Affordable Care Act: a trend analysis from MEPS 20072014. Med Care. 2017;55(8):771-780.

21. Lau JS, Adams SH, Park MJ, Boscardin WJ, Irwin CE Jr. Improvement in preventive care of young adults after the Affordable Care Act: the Affordable Care Act is helping. JAMA Pediatr. 2014;168(12): 1101-1106.

22. HealthyPeople.gov. Healthy People 2020. Access to health services. Accessed Jun 14, 2021. https://www.healthypeople.gov/2020/topicsobjectives/topic/social-determinants-health/interventions-resources/ access-to-health

23. Hatef E, Ma X, Rouhizadeh M, Singh G, Weiner JP, Kharrazi $H$. Assessing the impact of social needs and social determinants of health on health care utilization: using patient- and communitylevel data. Popul Health Manag. 2021;24(2):222-230.

24. Fiorati RC, Elui VM. Social determinants of health, inequality and social inclusion among people with disabilities. Rev Lat Am Enfermagem. 2015;23(2):329-336.

25. Lind KE, Hildreth KL, Perraillon MC. Persistent disparities in Medicare's annual wellness visit utilization. Med Care. 2019;57(12): 984-989.

26. Ashman JJ, Rui P, Okeyode T. Characteristics of office-based physician visits, 2016. NCHS Data Brief. 2019;(331):1-8.

27. Kaiser Family Foundation. Gender differences in health care, status, and use: spotlight on men's health. Published Mar 31, 2015. Accessed Jun 14, 2021. https://www.kff.org/womens-health-policy/ fact-sheet/gender-differences-in-health-care-status-and-use-spotlighton-mens-health/

28. Vaidya V, Partha G, Karmakar M. Gender differences in utilization of preventive care services in the United States. J Womens Health (Larchmt). 2012;21(2):140-145.

29. Novak JR, Peak T, Gast J, Arnell M. Associations between masculine norms and health-care utilization in highly religious, heterosexual men. Am J Mens Health. 2019;13(3):1557988319856739.

30. Cameron KA, Song J, Manheim LM, Dunlop DD. Gender disparities in health and healthcare use among older adults. J Womens Health (Larchmt). 2010;19(9):1643-1650.

31. Artiga $S$, Orgera K; Kaiser Family Foundation. Key facts on health and health care by race and ethnicity. Published Nov 12, 2019. Accessed Jun 14, 2021; https://www.kff.org/report-section/key-factson-health-and-health-care-by-race-and-ethnicity-coverage-access-toand-use-of-care/

32. Wilson R, Lewis SA, Dicianno BE. Targeted preventive care may be needed for adults with congenital spine anomalies. PM R. 2011;3(8): 730-738.

33. Mukherjee S, Pasulka J. Care for adults with spina bifida: current state and future directions. Top Spinal Cord Inj Rehabil. 2017;23(2): 155-167.
34. Whitney DG, Kamdar NS, Ng S, Hurvitz EA, Peterson MD. Prevalence of high-burden medical conditions and health care resource utilization and costs among adults with cerebral palsy. Clin Epidemiol. 2019;11:469-481.

35. Massachusetts Department of Developmental Services (DDS), Center for Developmental Disabilities Evaluation and Research (CDDER)/ UMass Medical School. Preventive health recommendations for adults with intellectual disability. Published 2019. https://shriver. umassmed.edu/sites/default/files/MA\%20DDS\%20health\%20screening\%20brochure_2019_final.pdf

36. American Academy for Cerebral Palsy and Developmental Medicine. Fact sheet: care of adults with cerebral palsy. Accessed Jun 14, 2021. https://www.aacpdm.org/UserFiles/file/fact-sheet-pcp-doc-101415.pdf

37. Turk MA. Health, mortality, and wellness issues in adults with cerebral palsy. Dev Med Child Neurol. 2009;51(Suppl 4):24-29.

38. Sullivan WF, Berg JM, Bradley E et al; Colloquium on Guidelines for the Primary Health Care of Adults With Developmental Disabilities. Primary care of adults with developmental disabilities: Canadian consensus guidelines. Can Fam Physician. 2011:57(5):541-553, e154-e168.

39. Abrahamson V, Jensen J, Springett K, Sakel M. Experiences of patients with traumatic brain injury and their carers during transition from in-patient rehabilitation to the community: a qualitative study. Disabil Rehabil. 2017;39(17):1683-1694.

40. Saunders LL, Ekoja E, Whitlock CS, DiPiro ND, Gregory-Bass R, Krause JS. A comparison of health behaviors between African Americans with spinal cord injury and those in the general population. NeuroRehabilitation. 2013;33(3):449-456.

41. Stillman MD, Frost KL, Smalley C, Bertocci G, Williams S. Health care utilization and barriers experienced by individuals with spinal cord injury. Arch Phys Med Rehabil. 2014;95(6):1114-1126.

42. American Stroke Association. Recovery and risk reduction to prevent a second stroke. Published Dec 2018. Accessed Jun 14, 2021. https://www.stroke.org/en/life-after-stroke/preventing-another-stroke

43. Joy JE, Johnston RB Jr, eds. Multiple Sclerosis: Current Status and Strategies for the Future. National Academies Press; 2001.

44. National Multiple Sclerosis Society. Wellness discussion guide for people with MS and their healthcare providers, integrating lifestyle and complementary strategies into MS care. Published 2016. Accessed Jun 14, 2021. https://nmsscdn.azureedge.net/ NationalMSSociety/media/MSNationalFiles/Brochures/BrochureWellness-Discussion-Guide-for-ppl-wMS-and-HCPs.pdf

45. National Multiple Sclerosis Society. Preventive care recommendations: the basic facts: multiple sclerosis. Published 2018. Accessed Jun 14, 2021. https://www.nationalmssociety.org/NationalMSSociety/ media/MSNationalFiles/Brochures/Brochure-Preventative-CareRecommendations-BasicFacts-FINAL.pdf

46. Dobos K, Healy B, Houtchens M. Access to preventive health care in severely disabled women with multiple sclerosis. Int J MS Care. 2015; 17(4):200-205.

47. National Center for Health Statistics. Summary health statistics: National Health Interview Survey, 2018. Table A-18a. Accessed Jun 14, 2021. https://ftp.cdc.gov/pub/Health_Statistics/NCHS/NHIS/SHS/ 2018_SHS_Table_A-18.pdf 